\title{
Fertilization of Algal Resources by an EXotic SNAIL MAY FACILITATE INVASION
}

\author{
LESLIE A. RILEY $\uparrow$ MARK F. DYBDAHL \\ SCHOOL OF BIOLOGICAL SCIENCES \\ WASHINGTON STATE UNIVERSITY $\uparrow$ PULLMAN
}

\author{
ROBERT O. HALL \\ ZOOLOGY AND PHYSIOLOGY \\ UNIVERSITY OF WYOMING $\uparrow$ LARAMIE
}

\section{$\downarrow \quad$ PROJECT SUMMARY}

Exotic species severely impact the environment in a variety of ways, but often, the mechanism allowing invasion is unknown. One exotic species, the New Zealand mud snail, attains high densities in western U.S. rivers, exceeding $500,000 / \mathrm{m}^{2}$ in some areas, and now occupies streams within the Snake and Madison watersheds in the Greater Yellowstone Ecosystem. Because the mud snail may strongly impact many stream communities, it is crucial to understand the mechanism of invasion. We studied interactions between the mud snails and their food source (algae) to determine how they may negatively (through consumption) and positively (through excretion of nitrogen) affect the resource. While most studies of consumer-resource interactions focus on the negative impact of the consumer, the presence of the consumer can also have positive effects on the resource and may help the mud snail establish in some streams. We conducted caged field experiments in Polecat Creek separating the effects of snail grazing and snail excretion on algal growth. We found that, although snails do decrease algae when grazing in high densities, there is relatively little decrease in algae at intermediate and low grazing densities. In addition, snail excretion alone increased algal growth. These results suggest that mud snails have a positive effect on the algal resource and this may facilitate invasion.

\begin{abstract}
$\uparrow \quad$ Abstract
We studied positive and negative effects of snail consumers on their resource to determine if positive consumer effects may be facilitating invasion. Consumer- resource interactions often focus on losses to the resource, even though the resource might benefit if consumers recycle nutrients. The New Zealand mudsnail, Potamopyrgus antipodarum, an exotic in western U.S. rivers, attains high densities and dominates macroinvertebrate communities. In one well-studied river, it consumes the majority of primary productivity, cycles most nitrogen and can grow faster at higher densities. In field experiments, we tested the hypothesis that this invasive grazer stimulates algal growth via nitrogen excretion, which might explain its self-facilitation and invasiveness. Using in-stream cages subdivided into "with snails" and "without snails" sections, we examined the response of periphytic algae to snail grazing and excretion and snail excretion alone at various levels of snail biomass. We found that chlorophyll $a$ and GPP (gross primary production) decreased as the biomass of snails increased in the grazed sections. Snail excretion, in the absence of grazing, increased both chlorophyll $a$ and GPP, demonstrating a positive effect of snails on the resource, consistent with the nutrient recycling and enrichment hypothesis. We found no evidence for increased algal growth at intermediate snail densities
\end{abstract}


in grazed treatments, as predicted by the Herbivore Optimization Curve hypothesis. However, the difference in chlorophyll $a$ between "with snails" and "without snails" treatments increased as snail biomass increased. This suggests that snail compensation of the resource, through excretion, decreases at extremely high levels of grazing pressure and the net effect of snail grazing becomes negative. Together, these results suggest that invasiveness in some rivers may be fostered by this self-facilitation and recycling of essential nutrients.

\section{$\downarrow \quad$ INTRODUCTION}

Invasive species are the second leading threat to the global biodiversity crisis, but much debate still exists about factors that control invasion success and it may be because a key component is missing. Many studies focus on negative interactions between the invader and the native community that limit the spread or establishment of the exotic species (i.e. biotic resistance of the invaded community (e.g. Kennedy et al 2002, Stachowicz et al 1999)). However, facilitative interactions between the native community and the invader may be just as important in determining whether an invader is successful (e.g. herbivores and plant invasion. Because most traditional ecological paradigms focus on negative interactions (i.e. Lotka - Volterra, etc.), facilitation has often been overlooked, but is becoming increasingly recognized as crucial to community organization (Bruno et al 2003). In addition, net effects are often examined, rather than positive and negative effects measured separately (Bruno et al 2003). If facilitative interactions vary in importance along an environmental gradient, negative effects may sometimes outweigh or equal positive effects, making it difficult to determine that positive interactions even exist.

One invasive aquatic herbivore, the New Zealand mud snail (a prosobranch gastropod), was first recorded in the western United States in 1987, and now has a widespread but patchy distribution, including several areas of conservation significance (i.e. Yellowstone and Grand Canyon National Park). In one stream (Polecat Creek) densities of Potamopyrgus have reached 500,000 adult snails $/ \mathrm{m}^{2}$ in some areas (Hall et al 2003). However, in other streams mud snails are present at low densities. This variation in densities among streams could be due to the relative importance of facilitative interactions in aiding mud snail establishment and proliferation.
Mud snails are scraping herbivores, feeding on periphytic algae and algal detritus. By increasing the number of mud snails, we expect chlorophyll $a$ standing crop to decrease via snail consumption. While previous work showed that chlorophyll $a$ concentrations declined, primary production remained constant over a large range of densities in Polecat Creek (Hall, unpublished data). This finding strongly contrasts that from the Firehole and Snake rivers, where lower densities of snails significantly lowered both primary production and chlorophyll standing stocks on rocks (Hall, unpublished data). Results in Polecat Creek, though, are consistent with the "herbivore optimization curve" (HOC) hypothesis (McNaughton 1979), which states that primary productivity is highest at intermediate grazing levels. Although the HOC hypothesis was developed to explain grazing in terrestrial systems, aquatic studies also support this phenomenon of positive consumer effects (reviewed in DeAngelis 1992). And while many studies support this assertion, the mechanism for the observed phenomenon is unclear in many cases. One leading hypothesis is that grazer presence may stimulate algal growth through excretion of limiting nutrients, such as nitrogen (Sterner 1986, Giannoti and McGlathery 2001).

Historically, consumer- resource interactions have focused on gains to the consumer and losses to the resource. Often, though, consumers affect recycling of nutrients that benefit the resource (DeAngelis 1992, Geddes and Trexler 2003). In Polecat Creek, nitrogen uptake velocity (demand relative to concentration) is extremely high, indicating that nitrogen is in high demand in this system (Hall et al 2003). The possibility exists that intermediate to high levels of snail grazing stimulate algal growth through nutrient enrichment (Giannoti and McGlathery 2001). Snails excrete nitrogen in the form of ammonium. Because ammonium can stimulate algal growth, snail excretion may increase the growth rate of algae, which is immediately grazed by snails (Hall et al 2003). Mud snails may therefore increase turnover rates and primary production of algae by simultaneously fertilizing and harvesting algae. At extremely high snail densities, intense grazing pressure may negate the fertilization effect and algal biomass would begin to decrease. Therefore, at low to intermediate densities, snails may rapidly renew algal resources, possibly facilitating invasion into streams with low production or low nutrient availability.

In this study, we tested the prediction that intermediate snail densities would lead to the highest levels of primary production, as hypothesized by the 
HOC, and that this is caused by snails excreting ammonium. Ammonium should fertilize algae and negate the negative impacts of grazing at intermediate snail densities. To test the HOC hypothesis, we assessed the effects of snail density on algal growth over a range of biomass treatments. In addition, we tested the snail excretion hypothesis by separately examining the effects of grazing and excretion on algal growth over a range of biomass treatments.

\section{$\uparrow \quad$ METHODS}

\section{Experimental design}

We performed two similar field experiments in Polecat Creek in the summer of 2003 to examine effects of snail grazing, snail excretion and snail density on algal growth. We tested effects of snail grazing using a range of snail biomass levels to determine if consumer-resource interactions were consistent with the "HOC" hypothesis. In addition, we examined snail grazing and snail excretion separately over the same range of snail biomass levels to determine if nutrient enrichment by snails positively affected the resource.

Experimental cages were constructed from $0.0256 \mathrm{~m}^{2}$ plastic sandwich trays by cutting large openings in the sides and top of each tray and then covering with window screen. This mesh allowed light to enter and water current to flow through the chambers. We glued a screen partition in the middle of the cage to divide each cage in half. Four rocks from the surrounding stream area were cleaned of benthic macro-invertebrates and placed in each side of each cage. We then added the appropriate number of snails to the upstream portion of each cage to yield the treatment biomass. Each treatment contained two replicates. While snails graze and excrete in the upstream portion of the cage, only snail excretion travels through the window screen to the downstream portion of the cage (Fig. 1). After 5-6 days, chlorophyll $a$ and primary production were measured from the side of the cage with snails present ("grazing") and from the side of the cage with snails absent ("excretion only"). In the first experiment, snail biomass treatments ranged from $0(0 \mathrm{mg}$ $\mathrm{AFDM} / \mathrm{m}^{2}$ ) to 30 times (9980 $\mathrm{mg} \mathrm{AFDM} / \mathrm{m}^{2}$ ) ambient snail biomass estimated from rocks in this stream (332 $\left.\mathrm{mg} \mathrm{AFDM} / \mathrm{m}^{2}\right)$. However, we saw little evidence, from the first experiment, that "grazing" treatments decreased algal production or standing stock. In the second experiment, to ensure the negative effects of grazing outweighed the positive effects of excretion, we increased snail biomass levels to $50 \mathrm{x}\left(16600 \mathrm{mg} \mathrm{AFDM} / \mathrm{m}^{2}\right)$ and eliminated the $5 \mathrm{x}$ and $10 \mathrm{x}$ treatments.

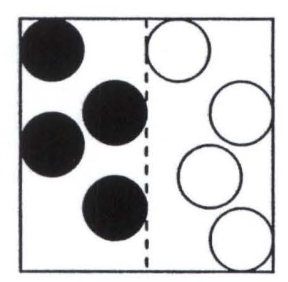

snails no snails

Figure 1. Schematic depicting a representative cage used in the experiment. Arrow depicts water current direction. The square represents one cage, with the dotted line representing the window screen partition separating the upstream and downstream portion of the cage. The circles represent rocks with periphytic algae. Snails were added (according to the appropriate biomass for each treatment) to the upstream portion of the cage. Therefore, "grazing" treatments represent areas where snails grazed and excreted (black), while "excretion only" treatments have no grazing, but do allow for snail excretion to flow in from the upstream portion of the cage (white).

To test the "herbivore optimization curve hypothesis" we measured algal biomass and primary productivity from all "grazing" treatments. Under the HOC hypothesis, we expected to see increased productivity at intermediate levels of snail grazing. To test if nutrient enrichment by snails is increasing algal growth, we compared control cages $(0 x)$ to the "excretion only" portion of experimental cages. Control cages, with snail excretion absent, should have less algae than treatments affected by snail fertilization. Also, we compared "grazing" and "excretion only" from all experimental cages, expecting the difference in the amount of algae between the two treatments to increase as snail biomass is increased.

\section{Primary production measurements}

To examine the effect of snail grazing and snail excretion on primary production, we incubated rocks from cages in clear and dark PVC plastic tubes through which water was continuously pumped. Oxygen concentrations were recorded at the start of the 
incubation and one hour later with a dissolved oxygen meter. The decrease in oxygen in the dark chamber represents community respiration (CR), while the change in oxygen in the clear chamber represents Net Primary Production (NPP). NPP+ $|\mathrm{CR}|$ $=$ Gross Primary Production, which is the rate of photosynthesis. We estimated rock surface areas after chlorophyll samples were collected (see below).

\section{Chlorophyll a measurements}

To examine the effect of snail grazing and snail excretion on algal biomass, we estimated chlorophyll $a$ concentrations on rocks from cages at the end of the experiment. Algal periphyton was brushed from the rocks and the slurry collected on glass fiber filter paper (Gelman AE, 0.9 micron pore size, $25 \mathrm{~mm}$ diameter) with $100-\mathrm{ml}$ syringes. We extracted chlorophyll from filters with $90 \%$ acetone and chlorophyll concentrations were then estimated with a spectrophotometer (APHA 1989). We estimated the exposed rock surface area from paper tracings.

\section{RESULTS AND DISCUSSION}

\section{HOC hypothesis}

\section{Experiment \#1:}

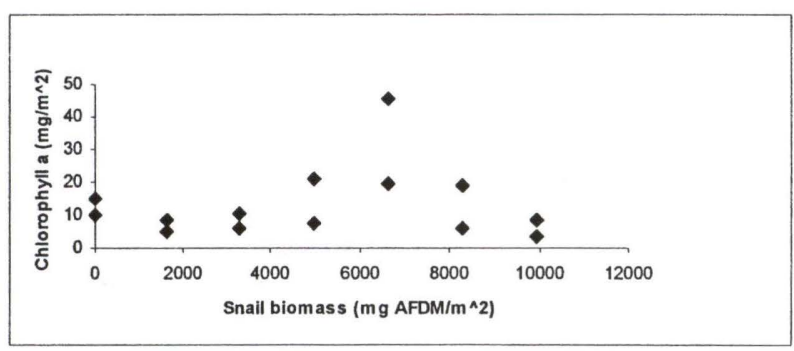

Figure 2a. Net effect of mud snails on the standing stock of algae in experiment 1 within grazer enclosures ("grazing" treatments).

In the first experiment, algal standing stock in the "grazing" treatment was highest between 5000 and $8000 \mathrm{mg}$ AFDM snails $/ \mathrm{m}^{2}$ (Fig. 2a). Above and below this level of snail biomass, the standing stock of algae was lower. Primary production measurements indicated that snail grazing caused a slight decrease in primary productivity at densities up to $10000 \mathrm{mg}$ AFDM snails $/ \mathrm{m}^{2}$ (Fig. 3a).

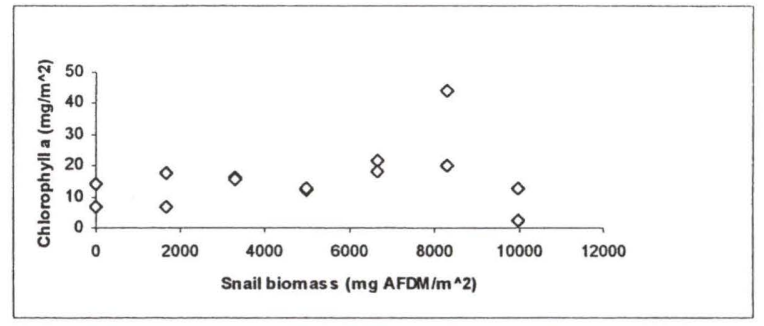

Figure $2 \mathrm{~b}$. Indirect effect of mud snails on standing stock of algae (no snails) in experiment 1 inside grazer exclosures ("excretion only" treatments).

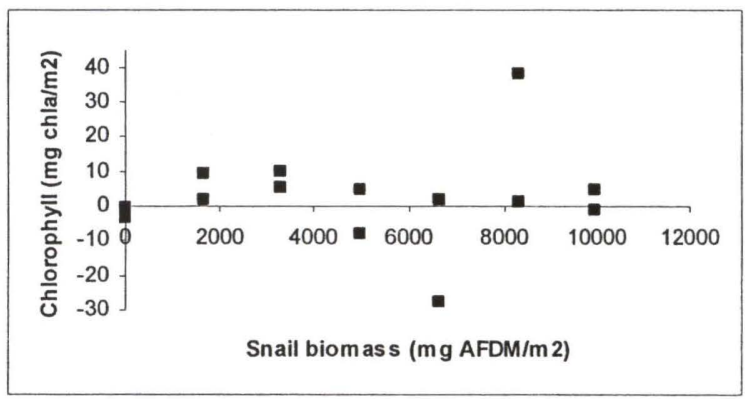

Figure 2c. Difference between the indirect effect of snails ("excretion only") in grazer exclosures and the direct effect of snails within enclosures ("grazing").

This evidence suggests that snails had a positive effect on algal resources. First, algal standing stock actually increased at intermediate snail densities. Second, primary production only decreased slightly even as the biomass of snails increased. This prompted us to explore grazing and fertilization effects at higher levels of grazer biomass. Therefore, in the second experiment, we increased the maximum snail biomass level to $16600 \mathrm{mg}$ AFDM snails $/ \mathrm{m}^{2}$.

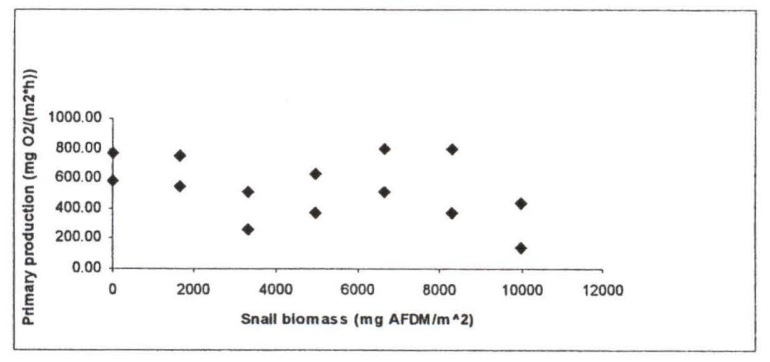

Figure 3a. Net effect of mud snails on GPP in experiment 1 within grazer enclosures ("grazing”). 


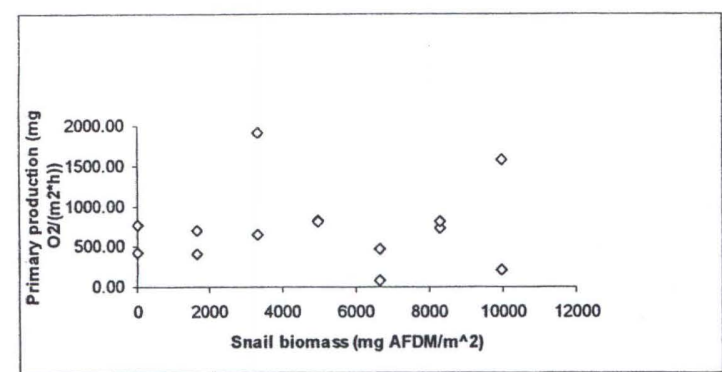

Figure $3 \mathrm{~b}$. Indirect effect of mud snails on GPP in experiment 1 inside grazer exclosures ("excretion only").

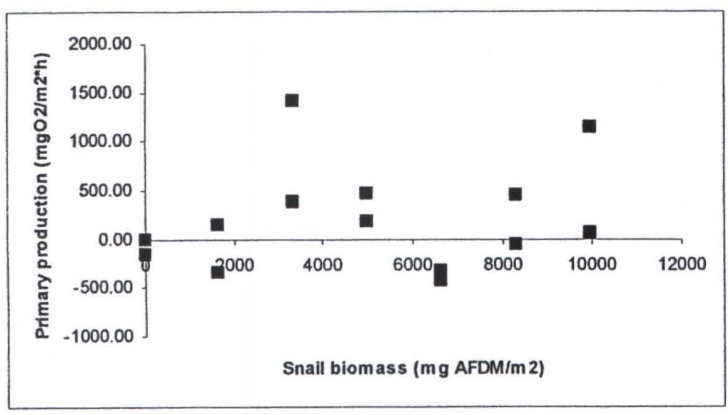

Figure 3c. Difference between the indirect effect of snails ("excretion only") in grazer exclosures and the direct effect of snails within enclosures ("grazing") in experiment 1.

In the second experiment, chlorophyll concentrations peaked in cages exposed to snail grazing at $5000 \mathrm{mg} \mathrm{AFDM} / \mathrm{m}^{2}$, but dropped more rapidly compared to the first experiment, with the lowest chlorophyll concentrations at a snail biomass of $6600 \mathrm{mg} \mathrm{AFDM} / \mathrm{m}^{2}$ (Fig. 4a). Chlorophyll concentrations did not vary between 10000 and $16600 \mathrm{mg}$ AFDM snails $/ \mathrm{m}^{2}$ (Fig. 4a). Overall, though, chlorophyll concentrations decreased from 0 $\mathrm{mg}$ AFDM snails $/ \mathrm{m}^{2}$ to $16600 \mathrm{mg}$ AFDM snails $/ \mathrm{m}^{2}$ (Fig. 4a). Primary production slightly decreased as intensity of snail grazing increased, especially above $8300 \mathrm{mg}$ AFDM snails $/ \mathrm{m}^{2}$ (Fig. 5a).

Experiment \#2:

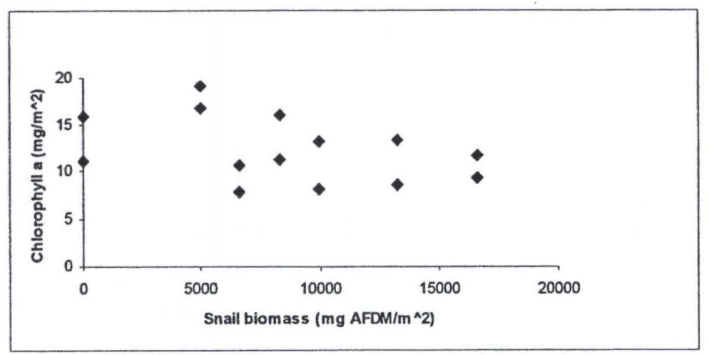

Figure 4a. Net effect of mud snails on the standing stock of algae in experiment 2 within grazer enclosures ("grazing").

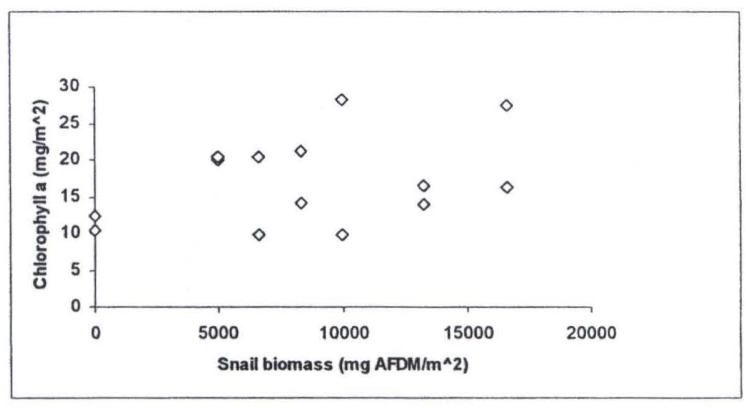

Figure $4 \mathrm{~b}$. Indirect effect of mud snails on standing stock of algae in experiment 2 inside grazer exclosures ("excretion only").

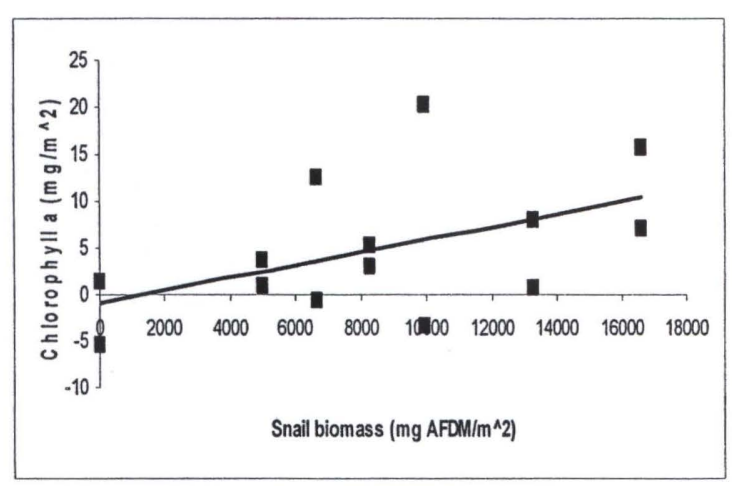

Figure 4c. Difference between the indirect effect of snails ("excretion only") in grazer exclosures and the direct effect of snails within enclosures ("grazing") in experiment 2.

Overall, these results suggest snails had both negative and positive effects on the resource. At low and intermediate snail densities, the net effect of grazing, on both gross primary production and chlorophyll concentrations, was either positive or neutral. When snail densities were extremely high, the net effect of grazing was negative on algal growth (primary production measurements) and on the standing stock of the resource (chlorophyll concentrations). While no evidence exists for a strong peak in production at intermediate grazing levels (HOC hypothesis), we saw that snails had both positive and negative effects on the resource. While other studies have also demonstrated positive consumer effects for aquatic organisms (e.g. Sterner 1986), no studies, to our knowledge, have demonstrated positive consumer effects for an aquatic invader. This facilitative interaction between herbivores and primary producers may prove to be extremely important for predicting invasion success in aquatic habitats.

\section{Nutrient enrichment hypothesis}

While most grazing studies only examine overall net effects, we wanted to examine the positive 
effects of snails on their food source. To do so, we compared "grazing," "excretion only," and control treatments from both experiments 1 and 2 . If snail excretion is stimulating algal growth, we expect the "excretion only" portion of experimental cages to have higher standing stock and production than the grazing side. We also expect "excretion only" treatments to have higher standing stock and production than control cages.

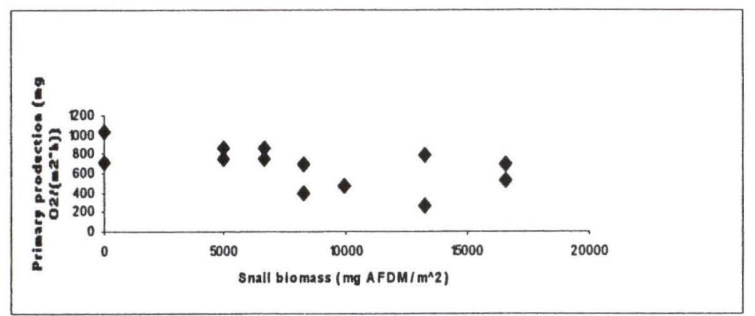

Figure 5a. Net effect of mud snails on GPP in experiment 2 within grazer enclosures ("grazing").

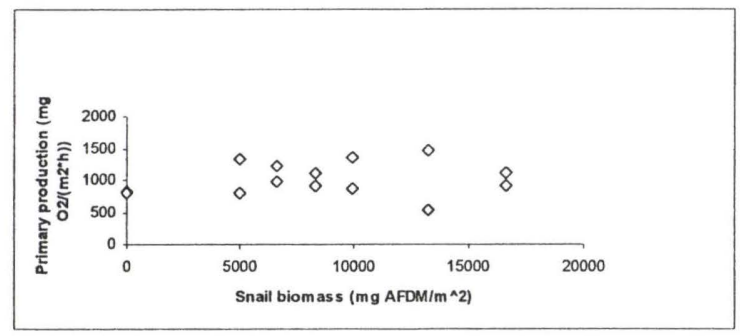

Figure $5 \mathrm{~b}$. Indirect effect of mud snails on GPP in experiment 2 inside grazer exclosures ("excretion only").

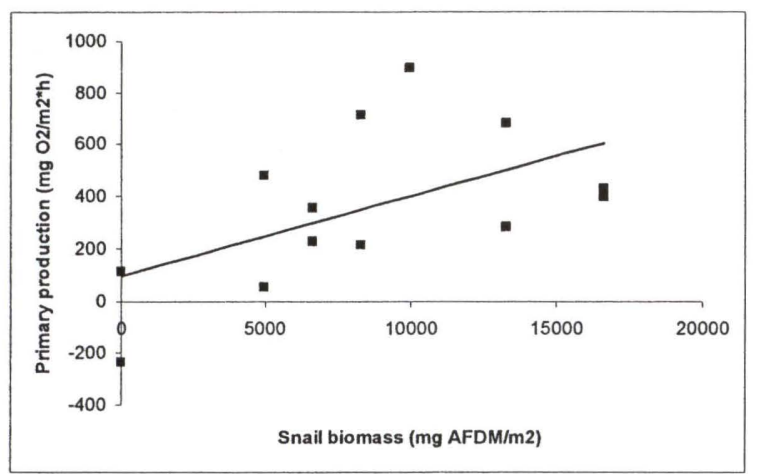

Figure 5c. Difference between the indirect effect of snails ("excretion only") in grazer exclosures and the direct effect of snails within enclosures ("grazing") in experiment 2.

In the first experiment, we found no differences in chlorophyll or primary production between "grazing" and "excretion only" treatments in experimental cages (Figs. 2c, 3c). In the second, higher-density experiment, "excretion only" treatments were consistently higher than "grazing" treatments in chlorophyll concentrations at higher snail densities ( $>5000 \mathrm{mg}$ AFDM snails $/ \mathrm{m}^{2}$ ) (Figs. 4a, $4 \mathrm{~b}, 4 \mathrm{c})$. In addition, chlorophyll concentrations in "excretion only" treatments from experimental cages were higher than control cages $(0 \mathrm{mg}$ AFDM snails $/ \mathrm{m}^{2}$ ). Also, as the biomass of snails increased, the level of chlorophyll in the "excretion only" treatments also increased (Fig. 4c). Primary production was also higher in "excretion only" treatments, when compared to "grazing" treatments (Figs. 5a, 5b, 5c). However, primary production was only slightly higher with increasing snail biomass (Fig. 5c). Overall, the presence of snails upstream from the "excretion only" treatments had a net positive effect on algal standing stock and production when snail biomass was high.

\section{CONCLUSIONS}

These results suggest that snail excretion may positively affect algal resources by stimulating growth in Polecat Creek. Because nitrogen cycling is tight and snails consume the majority of primary productivity in Polecat Creek (Hall et al 2003), excretion of nitrogen by snails may be an important determinant of periphytic algae productivity. This mechanism could create an avenue for successful mud snail invasion. However, the relative importance of nutrient recycling by snails could differ among streams, and influence invasion success, although this has never been studied explicitly. In streams, the role of animal-mediated nutrient cycling could potentially differ along productivity gradients (Vanni 2002), as suggested by some research in lakes. Excretion by animals in unproductive lakes, with lower nutrient availability, may influence primary production levels more than in productive lakes (Attayde and Hansson 2001). If the relative importance of nutrient cycling by mud snails differs between streams, we may be able to predict in which environments they are likely to be successful by studying both nutrient cycling and productivity. While mud snails cycle nutrients in every stream, it may only be in areas where nutrients are in high demand or scarce that this cycling of nutrients will confer an advantage to their spread. Larger invertebrates may not recycle nutrients at the same rate or volume and mud snails may possess the ability to take advantage of places where nutrients may be limiting. Mud snails, therefore, may out-compete other natives in streams where animal-mediated nutrient cycling plays an important role in regulating algal production. 


\section{LITERATURE CITED}

APHA. 1989. Standard methods for the examination of water and wastewater. Port City Press: Baltimore, Maryland.

Attayde J. L. and L. A. Hansson. 2001. Fishmediated nutrient recycling and the trophic cascade in lakes. Canadian Journal of Fisheries and Aquatic Sciences 58: 1924 1931.

Bruno, J. F., J. J. Stachowicz and M. D. Bertness. 2003. Inclusion of facilitation into ecological theory. TRENDS in Ecology and Evolution 18 (3): 119 - 125.

DeAngelis, D.L. 1992. Dynamics of nutrient cycling and food webs. Chapman and Hall: New York.

Geddes, P. and J. C. Trexler. 2003. Uncoupling of omnivore-mediated positive and negative effects on periphyton mats. Oecologia 136 : $585-595$.

Giannotti, A.L. and K.J. McGlathery. 2001. Consumption of Ulva lactuca (Chlorophyta) by the omnivorous mud snail Ilyanassa obsolete (Say). Journal of Phycology 37:209-215.
Hall, R. O., J. L. Tank and M. F. Dybdahl. 2003. Exotic snails dominate nitrogen and carbon cycling in a highly productive stream. Frontiers in Ecology and the Environment 1: 407-411.

Kennedy, T.A., S. Naeem, K. M. Howe, J. M. H. Knops, D. Tilman and P. Reich. 2002. Biodiversity as a barrier to ecological invasion. Nature 417: 636- 638.

McNaughton, S.J. 1979. Grazing as an optimization process: grass ungulate relationships in the Serengeti. American Naturalist 113: 691 703.

Stachowicz, J.J., R. B. Whitlach and R. W. Osman. 1999. Species diversity and invasion resistance in a marine ecosystem. Science 286: 1577 - 1579 .

Sterner, R. W. 1986. Herbivores' direct and indirect effects on algal populations. Science 231: $605-607$.

Vanni, M. J. 2002. Nutrient cycling by animals in freshwater ecosystems. Annual Review of Ecology and Systematics 33: $341-370$. 